\title{
Mergers and Acquisitions with a reference to Ethical, Social and Human Resource
}

\author{
${ }^{1}$ Mayur Taneja, ${ }^{2}$ Noopur Saxena \\ ${ }^{1}$ Assistant Professor Rajdhani College University of Delhi \\ ${ }^{2}$ Assistant Professor Bhagini Nivedita College University of Delhi
}

\begin{abstract}
Mergers and acquisitions are used by firms to strengthen and maintain their position in the market place. It is a way for companies to grow and expand into new markets, incorporate new technologies and to innovate and this business is rapidly increasing.Yet their success is by no means assured. To the contrary, a majority fall short of their stated goals and objectives. As a consequence, there are numerous social costs, including lost jobs, lost income to families and lost taxes to the local communities. Most of these social costs are not there when mergers and acquisitions are successful. While some failure can be explained by financial and market factors, a substantial number can be traced to neglected ethical, social \&human resource issues and activities.These issues have to be resolved in order to ensure a successful merger. This paper coverstypes of mergers and acquisitions, the reasons for their successes and failures\& will highlight Ethical, Social and Human Resource issues that need to be addressed while undertaking $M \& A$ activities, followed by an overview of recommendations for companies \& employees.
\end{abstract}

Key Words: Merger, Acquisition, Ethical Issues, Social Issues, Human Resource Issues

\section{Introduction}

Many companies today, in order to survive and grow, need and want to be efficient, profitable, flexible, adaptable, and have a dominant market position. Without these qualities, firms believe that is virtually impossible to be competitive in today's global economy. In some industries such as insurance or banking, firms may move into new markets. In others such as pharmaceuticals or software technology, firms may work with smaller firms that have developed or are developing new products that they can manufacture and/or distribute more efficiently, while other firms focus on their own internal growth, leadership and development. Regardless of the industry, however, it appears that it has become increasingly difficult in our global environment for firms to compete with others without growing and expanding through deals that result in mergers or acquisitions.

India in the recent years has showed tremendous growth in the M\&A deal. It has been actively playing in all industrial sectors. It is widely spreading far across the stretches of all industrial verticals and on all business platforms. The increasing volume is witnessed in various sectors like that of finance, pharmaceuticals, telecom, FMCG, industrial development, automotives and metals.

The volume of M\&A transactions in India has apparently increased to about 67.2 billion USD in 2010 from 21.3 billion USD in 2009. At present the industry is witnessing a whopping $270 \%$ increase in M\&A deal in the first quarter of the financial year. This increasing percentage is mainly attributed to the increasing crossborder M\&A transactions. Over that increasing interest of foreign companies in Indian companies has given a tremendous push to such transactions. Some of the major factors resulting in this sudden growth of merger and acquisition deal in India are favorablegovernment policies, excess of capital flows, economic stability, corporate investments and dynamic attitude of Indian companies. The recent merger and acquisition 2011 made be Indian companies worldwide are those of Tata Steel acquiring Corus Group plc, UK based company with a deal of US\$ 12,000 million and Hindalco acquiring Novelis from Canada

for US\$ 6,000 million.

With these major mergers and many more on the annual chart, M\&A services in India is taking a revolutionary form. The purpose of this paper is to articulate a systematic, social, ethical \&people-oriented approach for effectively doing mergers and acquisitions from beginning to integration and post-integration.

\section{Mergers and Acquisitions}

In a merger, two organizations join forces to become a new business, usually with a new name. Laws in India use the term Amalgamation for merger.

In an acquisition, on the other hand, one business buys a second and generally smaller company which may be absorbed into the parent organization or run as a subsidiary.

There are many types of mergers and acquisitions that redefine the business world with new strategic alliances and improved corporate philosophies. From the business structure perspective, some of the most common and significant types of mergers and acquisitions are listed below: 


\section{Horizontal Merger}

This kind of merger exists between two companies who compete in the same industry segment. The two companies combine their operations and gains strength in terms of improvedperformance, increased capital, and enhanced profits. This kind substantially reduces the numberof competitors in the segment and gives a higher edge over competition for e.g. Lipton India \& Brooke Bond.

\section{Vertical Merger}

Vertical merger is a kind in which two or more companies in the same industry but in differentfields combine together in business. In this form, the companies in merger decide to combine allthe operations and productions under one shelter. It is like encompassing all the requirements\& products of a single industry segmentfor e.g. Pixar-Disney Merger.

\section{Co-GenericMerger}

Co-generic merger is a kind in which two or more companies in association are some way or theother related to the production processes, business markets, or basic required technologies. Itincludes the extension of the product line or acquiring components that are all the way requiredin the daily operations. This kind offers great opportunities to businesses as it opens a huegateway to diversify around a common set of resources and strategic requirements.

\section{Conglomerate Merger}

Conglomerate merger is a kind of venture in which two or more companies belonging todifferent industrial sectors combine their operations. All the merged companies are no wayrelated to their kind of business and product line rather their operations overlap that of eachother. This is just a unification of businesses from different verticals under one flagshipenterprise or firm for e.g. Walt Disney Co. \& The American Broadcasting Co.

\section{Reasons for Merger}

There are numerous reasons for companies to merge or acquire. Some of the most frequent include:

- Mergers for market dominance; economies of scale.

- Mergers for channel control.

- Mergers for risk spreading, cost cutting, synergies, defensive drivers.

- Growth for world class leadership and global reach.

- Survival; critical mass; sales maximization.

- Acquisition of cash, deferred taxes, and excess debt capacity.

- Move quickly and inexpensively.

- Flexibility; leverage.

- Bigger asset base to leverage borrowing.

- Adopt potentially disruptive technologies.

- Financial gain and personal power.

- Gaining a core competence to do more combinations.

- Acquiring talent, knowledge, and technology

\section{Reasons for Success}

Perhaps not surprisingly some of the major reasons for success in mergers and acquisitions include:

- Leadership

- Well-thought out goals and objectives

- Due diligence on hard and soft issues

- Well-managed M \& A team

- Successful learning from previous experience

- Planning for combination and solidification steps completed early

- Key talent retained

- Extensive and timely communications to all stakeholders.

\section{Reasons for Failure}

Mergers and acquisitions fail for a variety of reasons, such as:

$\circ$ Expectations are unrealistic.

- Hastily constructed strategy, poor planning, unskilled execution.

- Failure/inability to unify behind a single macro message.

- Talent is lost or mismanaged. 
- Power and politics are the driving forces, rather than productive objectives.

- Requires an impossible degree of synergy.

- Culture clashes between the two entities go unchecked.

- Transition management fails.

- The underestimation of transition costs.

- Financial drain.

- Defensive motivation.

- Focus of executives is distracted from the core business.

\section{Ethical Issues in Mergers \& Acquisitions}

With the recent mergers and friendly and unfriendly takeovers, two important issues have not received sufficient attention as questionable ethical practices. One has to do with the rights of employees affected in mergers and acquisitions and the second concerns the responsibilities of shareholders during these activities. Although employees are drastically affected by a merger or an acquisition because in almost every case a number of jobs are shifted or even eliminated, employees at all levels are usually the last to find out about a merger transaction and have no part in the takeover decision. Second, if shareholders are the fiduciary beneficiaries of mergers and acquisitions, then it would appear that they have some responsibilities or obligations attached to these benefits. Broadly speaking:

Utilitarian approach: It views ethics of a merger activity from the perspective of gains and losses or as actions that will increase or reduce efficiency

Rights approach: It holds that any action that violates anyone's rights is unethical whether it is a positive sum game or even if majority benefits from the action to opposing a merger.

Social Issues in Mergers \& Acquisitions

The social issues include matters like:

$>$ the name of the combined entity

$>$ the location of its headquarters

the composition of the combined board and most importantly,

$>$ who will lead the combined company after the closing of the transaction.

Some mergers are likely to lessen Competition \& reduced competition in turn can lead to:

$>$ Higher prices, reduced availability of goods or services, lower quality of products, and less innovation

\begin{tabular}{|c|c|}
\hline Social Affects & Resulting in \\
\hline Decision-making style & $\begin{array}{l}\text {-Effective integration requires rapid decision-making. } \\
\text {-Different decision-making styles can lead to slow decision-making, failure to } \\
\text { make decisions, or failure to implement decisions. }\end{array}$ \\
\hline $\begin{array}{l}\text { Leadership style (for example: dictatorial } \\
\text { or consultative, clear or diffuse) }\end{array}$ & $\begin{array}{l}\text {-A shift in leadership style can generate turnover among employees who object } \\
\text { to the change. This is especially true for top talent, who are usually the most } \\
\text { mobile employees. } \\
\text { - Loss of top talent can quickly undermine value in integration by draining } \\
\text { intellectual capital and market contacts. }\end{array}$ \\
\hline $\begin{array}{l}\text { Ability to change (willingness to take risk } \\
\text { for new things, compared with focus on } \\
\text { maintaining current state and meeting } \\
\text { current goals) }\end{array}$ & $\begin{array}{l}\text {-Unwillingness to implement new strategies. } \\
\text {-Unwillingness to work through the inevitable difficulties in creating a new } \\
\text { company. }\end{array}$ \\
\hline $\begin{array}{l}\text { How people work together (for example: } \\
\text { based on formal structure and role } \\
\text { definitions or based on informal } \\
\text { relationships) }\end{array}$ & $\begin{array}{l}\text {-Merged companies will create interfaces between functions that come from } \\
\text { each legacy company, or new functions that integrate people from both legacy } \\
\text { companies. If the cultural assumptions of the legacy companies are inconsistent, } \\
\text { then processes and handoffs may break down with each company's employees } \\
\text { becoming frustrated by their colleagues' failure to understand or even recognize } \\
\text { how work should be done. }\end{array}$ \\
\hline $\begin{array}{l}\text { Beliefs regarding personal "success" } \\
\text { (for example: organizations that focus on } \\
\text { individual "stars," or on teamwork, or } \\
\text { where people rise through connections } \\
\text { with senior practitioners) }\end{array}$ & $\begin{array}{l}\text {-Again, these differences can lead to breakdowns in getting work done. If people } \\
\text { who believe they have to achieve goals as a team integrate with people whose } \\
\text { notion of "success" emphasizes individual performance, the resulting situation is } \\
\text { often characterized by personal dislike and lack of support for getting the job } \\
\text { done. }\end{array}$ \\
\hline
\end{tabular}

\section{Human Resource Issues in Mergers\& Acquisitions}

Merger \& Acquisition has a great impact on:

$>$ The employees working in a company \&on working conditions.

$>$ The main reason for failure of merger in most of the cases is non-integration of human resources of both the transferor and transferee company.

Some of the significant concerns and issues related to the human resource are: 
$\checkmark$ Due to merger, there is a clash between the companies which pulls them together into different direction apart from their aims \& objectives.

$\checkmark$ An M\& A activity without recognizing the impact on the human element results in lost revenue, customer dissatisfaction, employers attrition issues and so on.

$\checkmark$ Many personnel issues such as salaries, benefits, pension of employees are also affected due to M\&A.

$\checkmark$ Ego clashes between the top management.

$\checkmark$ Employees often become withdrawn and frustrated when their potential for future growth within the organization dwindles.

$\checkmark \quad$ M\&A affects the CEOs of the company.

$\checkmark$ Transfer, retrenchment and the loss of position in the hierarchical level.

$\checkmark$ M\&As shift the focus of employees from productive work to issues related to interpersonal conflicts, layoffs, career growth with the acquirer company, compensation etc.

$\checkmark$ Conflict in values and culture increases stress level among employees.

\section{Recommendations for Companies \& HR:}

There are numerous recommendations and conclusions that can be made about M\&A activity, especially at the company level and at the HR level.

$>$ Business and integration strategies must be clear.

The social costs must be articulated and understood.

$>$ Performance expectations must be reasonable and take into account market conditions, capital investment requirement, etc. Inflated performance expectations can lead executives to adopt short-term focus and delay making investments in the business.

$>$ Creating synergy between cultures such that employee at every level get satisfied by calling meeting, sharing ideas of the employees of both the companies using MBO (management by objectives ) Pre mergers meeting must be held to tell why merger is necessary, try to have creative, open, frequent one on one communication about the upcoming changes.

> Manager must ensure that employees perceive actions by management as being fair, unbiased and evenly distributed across both companies. Manager must ensure that employees feel that management understands their demands and "feels their pain" and supports them as people. Managers should strongly encourage employees to abandon the old and embrace the new.

$>$ Recognize that employees practicing extra role behaviors and enjoying high job satisfaction when merging look for partners whose company culture, practices, management styles are similar to their own, avoid discontinuity when acquiring, promote past managerial successes in similar endeavors to build employee trust that management has done this before and can be trusted to be successful.

$>$ Employee communications, retention of key employees and cultural integration are the most important activities in the HR area for successful M\&A integration.

$>$ Acquired companies often view their culture as faster moving than that of their new, larger parent. It is possible that each side will perceive its culture as "better" and does not want to give it up. Unmanaged cultural differences will lead to miscommunications and misunderstandings.

\section{Conclusion}

If success is to be achieved in M\&A, a cohesive, well integrated and motivated workforce is required who is willing to take on the challenges that arise in the process of M\&A. Along with this, an utmost care has to be taken to address all the ethical and social issues generated out of M\&As genuinely and sincerely. This contribution will be beneficial to the employees, shareowners, communities, suppliers and customers of the companies involved in the merger or acquisition activity.

\section{References}

[1] Evans, P., P.Barsoux, and V. Pucik (2002) Global HRM Challenge (London: McGraw-Hill);

[2] (2001) "The Great Mergers Wave Breaks," The Economist (January 27: 59-60); S. Kapner (2002),"Banking Mergers Gain Momentum in Europe," The New York Times (April 24:1 and 7).

[3] L. M. Holson (2000) "Whiz Kid: Young Deal Maker is a Force Behaind a Company's Growth,"

[4] The New York Times on the Web, June 28; O'Reilly, C. and Pfeffer, J. (2000) Hidden Value: How Great Companies Achieve Extraordinary Results with Ordinary People (Boston: Harvard Business School Press) : 49-77

[5] HR issues, activities and responsibilities in mergers and acquisitions by Randall S. Schuler and Susan E. Jackson, School of Management and Labour Relations, Rutgers University, New Brunswick, NJ, USA

[6] http://www.mergersandacquisitions.in/merger-and-acquisition-in-india.htm

[7] Charman; Carey, D. (2000) “A CEO Roundtable on Making Mergers Succeed,” Harvard Business Review (May- June: 145-154);

[8] Charman; Sparks; Hamel and Doz

[9] Two ethical issues in mergers and acquisitions, Patricia H. Werhane, Journal of Business Ethics, January/February 1988, Volume 7, Issue 1-2, pp 41-45

[10] Cultural issues in mergers and acquisitions, Deloitte Consulting LLP

[11] Conclusions based upon the studies of J \& J, Watson Wyatt, A.T. Kearney, The Delta Consulting Group, and Charman. 